\title{
Relative influence of brushing force transmission factors on substance loss of eroded dentine
}

\author{
Kazuo Kato*1, Yuya Soga ${ }^{1}$, Kiyomi Tamura ${ }^{1}$, Taeko Murakami ${ }^{1}$ and Yoshihiro Shimazaki ${ }^{1}$ \\ ${ }^{1}$ Department of Preventive Dentistry and Dental Public Health, School of Dentistry, Aichi Gakuin University, Nagoya, Japan
}

\begin{abstract}
This study was carried out to evaluate the influence of factors (such as tip form, brush tension and slurry viscosity) transmitting brushing force onto eroded dentine surface by measuring thickness of substance loss using an electron probe micro-analyzer.

Dentine slabs each with an exposed window $\left(4 \mathrm{~mm}^{2}\right)$ made using nail varnish were eroded through immersion into $0.83 \mathrm{M}$ acetic acid for 30 minutes. Half of the window area was then covered with nail varnish and served as the control area. The slabs were fixed and the tips (flat trim or tapered) of the bristles were placed on the eroded window, applying adequate pressures $\left(2 \mathrm{~g}\right.$ or $4 \mathrm{~g}$ per $\left.\mathrm{mm}^{2}\right)$ respectively. The slabs were then brushed for one minute using a sonic toothbrush (480 $\left.\mathrm{Hz}\right)$ with slurry containing silica abrasive and aqueous solutions of carboxymethylcellulose ( $0.5 \%$ or $1 \%)$ in a ratio of $10 \mathrm{~g}$ to $50 \mathrm{~mL}$. The slabs from which the nail vanish was removed were then sputter-coated with platinum and embedded in methacrylate to be cross-sectioned in the middle of the windows. The cross-sectional surface was polished, coated with carbon and examined using backscattered electron imaging to measure the thickness of dentine loss in the brushed and the control areas within the window.
\end{abstract}

The loss values $(\mu \mathrm{m}$, mean $\pm \mathrm{SD})$ in the treated and the control areas were $24.6 \pm 3.61$ and $21.5 \pm 3.36$ respectively. ANOVA analysis indicated that abrasion thicknesses defined as the differences of loss values between brushed and control surfaces were affected only by tip form with no significant interactions among the other factors. Eroded dentine wear by a sonic toothbrush was deeper with tapered tip $(3.82 \pm 2.73)$ than with flat trim $(2.40 \pm 1.54)$.

The results suggested that the influence of factors transmitting brushing force on eroded dentine wear was limited.

\section{Introduction}

Dental erosion is chemical wear as a result of extrinsic or intrinsic acids or chelators acting on plaque-free tooth surfaces and dissolution of tooth by acids when the surrounding aqueous phase is undersaturated with respect to tooth mineral [1]. The critical $\mathrm{pH}$ for dentine dissolution, being presumed at least as high as $\mathrm{pH} 6.0$ [2] is considerably higher than that of enamel cited as around $\mathrm{pH}$ 5.4. Therefore, once dentine is exposed by loss of enamel or periodontal tissues, the risk of dentine erosion will be increased by behavioral factors including excessive consumption of acidic foods and drinks, unusual eating and drinking habits, etc. [3]. It has been well known that frequent toothbrushing with abrasive oral hygiene products may enhance the abrasion of eroded dentine [4-9].

Clinical [10], in situ [4,9,11] and in vitro [5-8] studies have been conducted to understand the complex nature of erosive dentine wear. In these studies, various techniques that were used to assess the mineral loss of dental hard tissues, such as microradiography [6,7], microhardness test [8], surface 3D topography [8] and scanning electron microscopy [7] have been applied to evaluate the influence of acid on dentine loss and the assessment of erosive dentine wear by toothbrushing. Optical $[6,7]$ and mechanical $[4-9,11]$ profilometry are techniques that have also been frequently applied for the same propose. The former could detect surface roughness and substance loss of eroded dentine by scanning specimens with a laser beam and the latter by loading the contact stylus laterally across specimens for a specified distance and specified contact force.

Ganss, et al. [6] investigated the effects of toothbrushing on eroded dentine by optical and mechanical profilometry, and longitudinal microradiography. However, the results revealed widely significant differences in substance dentine loss among the different methods, indicating that the optical profilometry yielded the lowest and the microradiography the highest substance loss values. A softened demineralized organic layer develops on the surfaces of eroded dentine and is different from that of eroded enamel. The outermost layer is very susceptible to mechanical forces so that measurements by contact profilometers could be effected by the stylus to penetrate this fragile layer. Optical profilometry of eroded dentine also might interfere with the exposed collagen matrix, not reflecting mineral loss of the bulk dentine specimen adequately. Thus the assessment of the influence of erosion or erosion followed by abrasion on dentine is probably influenced by what the technique detects as the surface of the demineralized dentine. Therefore, it would be ideal for the evaluation of erosive dentine wear to detect visibly the outermost surface of the

Correspondence to: Kazuo Kato, Department of Preventive Dentistry and Dental Public Health, School of Dentistry, Aichi Gakuin University, Nagoya, Japan, E-mail: kazkato@dpc.aichi-gakuin.ac.jp

Key words: transmission of brushing force, eroded dentine, tooth wear, electron probe micro-analyzer

Special Issue: Early Caries (Surbsurface Demineralization)

Shigeru Watanabe, DDS, PhD

Professor of Division of Pediatric Dentistry,

School of Dentistry, Meikai University, Japan

Published: April 12, 2017 
fragile organic layer of eroded dentine when the extent of eroded dentine wear is defined as the depth to which tissue has been lost.

Recently, authors have developed a new method to accurately evaluate the effect of an oral irrigator on the removal of plaque biofilm by measuring the thickness of in vivo plaque biofilm accumulated on a tooth surface using an electron probe micro-analyzer (EPMA) [12]. To be brief, the freeze-dried biofilms on enamel slabs, whose surfaces had been treated with a dental water jet, were sputter-coated with platinum to examine their surfaces using secondary-electron imaging. The cross-sections of the biofilm slab units were then examined using backscattered electron compositional (COMPO) imaging. A thin layer of platinum that coincided with the outer surface of the biofilm could be easily identified by atomic number contrast using the COMPO images. This technique was adapted to an in vitro study that was carried out to quantitatively evaluate the abrading action of a sonic toothbrush on eroded dentine by measuring the depth of dentinal loss using the COMPO images. Although the images were used to identify the outer surface of demineralized dentine layer as a clear and fine outline of platinum, the results indicated that brushing with a sonic toothbrush had little influence on the loss of eroded dentine irrespective of toothpaste [13].

Clinical data and studies in vitro show that the major abrasive agent is toothpaste. Brushing without toothpaste has very small clinical effects on dentine but features of the toothbrush can modulate the abrasivity of the toothpaste [14]. Several factors such as brushing force, means of transmitting the power to the dentine surface and the circumstance in which the abrasive particles were placed might affect the rate of dentine wear by dentifrice abrasiveness. The purpose of this study was to evaluate the influence of factors (tip form, brush tension and slurry viscosity) transmitting brushing force onto eroded dentine surface by measuring the thickness of substance loss.

\section{Materials and methods}

Slices of tooth crown (app. $4 \mathrm{~mm}$ thick) were taken from the cervical area of surgically extracted third molars that were stored in a $10 \%$ formalin neutral buffer solution. Sixty-four dentine slabs $(4 \times 4$ $\mathrm{mm}$ ) were taken from the slices from which the enamel was removed with water-cooled silicon carbide discs. Each slab was placed with the outer surface in the top part of a $8 \mathrm{~mm}$ flat-bottomed polyethylene capsule (C094, Taab, UK) and embedded with methyl methacrylate. The outer surface of dentine was polished using silicon carbide discs and paste of alumina powder $(0.3 \mu \mathrm{m})$ on a rotating polishing machine (Scandimatic universal, SCAN-DIA, Germany) under sufficient water flow. Subsequently, the embedded samples were sonicated for $10 \mathrm{~min}$ in distilled water and were then air dried.

An exposed window $(2 \times 2 \mathrm{~mm})$ was made in the center of the polished dentine surface using nail varnish, and the embedded block was immersed in $0.83 \mathrm{M}$ acetic acid $(\mathrm{pH} 2.3$ ) for 30 min using a magnetic stirrer. After the erosive treatment, the samples were rinsed with distilled water and then air dried. Half of the window area was then covered with nail varnish and served as the control surface.

The embedded block was fixed by inserting into the cylindroid hole of the acrylic stage on which a head of toothbrush could be located on the fixed block by acrylic guides without any obstruction of sonic brush movement. Tips (tapered ${ }^{\star} 1$ or flat trim ${ }^{\star} 2$ ) of the bristles were placed on the eroded window perpendicular to the window floor, applying adequate pressures $\left(2 \mathrm{~g}\right.$ or $4 \mathrm{~g}$ per $\left.\mathrm{mm}^{2}\right)$, respectively. The window surfaces were then brushed for 1 min using the normal mode $(480 \mathrm{~Hz})$ of a sonic toothbrush (Dent EX Systema; Vibrato Care, Lion, Japan) with slurry containing silica abrasive (Sorbosil AC77, RDA125; PQ Corporation, UK) and aqueous solutions of carboxymethylcellulose $(0.5 \%$ or $1 \%)$ at a ratio of $10 \mathrm{~g}$ to $50 \mathrm{~mL}$. The experimental brush head with flat trim bristles was prepared by fixing the head of manual toothbrush with flat-trim bristles to a replacement brush head of the sonic toothbrush.

After the treatment with a sonic toothbrush, the samples were cleaned ultrasonically, dipped in acetone to remove the nail varnish and air-dried. The window areas with and without the treatment were subsequently sputter-coated with $20 \mathrm{~nm}$ platinum and embedded in methacrylate to be cross-sectioned in the middle of the windows. The cross-sectional surface was polished as mentioned above, coated with $15-20 \mathrm{~nm}$ of carbon, and examined using the backscattered electron detector equipped with a field emission EPMA (JXA-8530FA; JEOL, Japan) with an accelerating voltage set to $15.0 \mathrm{kV}$. The COMPO image $(\times 40$; Figure 1$)$ of cross-section of whole eroded window was taken at the center of the slab surface and another two COMPO images of half of the window area of both sides were taken including the boundary between the eroded and sound dentine at 200 magnification to measure the thickness of dentine loss on the brushed and control surfaces within the window (Figure 2).

The line was drawn between the original surfaces which remained on both sides of the window on the COMPO image of lower magnification and the tilt of the line to a horizontal plane (Figure 1) was measured using image-analysis software (Image Pro-Plus J6.2, Media Cybernetics, MD, USA). Subsequently the tilt of another two higher magnification images were adjusted horizontally to calculate areas of substance loss across certain widths between the original dentine surface and the erosive window floor indicated by the thin platinum layer (Figure 2). The effect of erosive dentine wear by sonic toothbrushing was estimated using the differences in the average thickness of substance loss between a pair of treated and control window areas. The formula to evaluate abrasion thickness was shown in Figure 2.

Data were statistically analyzed by three-factor crossed mixed model ANOVA considering tip form, brush tension and slurry viscosity as independent variables. The factors and number of samples analyzed were shown in Table 1 . When statistical significances were found in factors, or interactions between factors, differences in abrasion thickness were examined between the treated and control windows using a paired t-test. The analyses were performed using a statistical package (IBM SPSS Statistics 21.0J, IBM Japan, Tokyo, Japan). The level of significance was set at 0.05 . Several samples that were lost during the experimental processes were treated as missing values.

\section{${ }^{\star}$ 1: Lion DENT EX Systema Vibrato Care S (left)}

\section{*2: Lion DENT EX Slimhead II 34 S (right)}
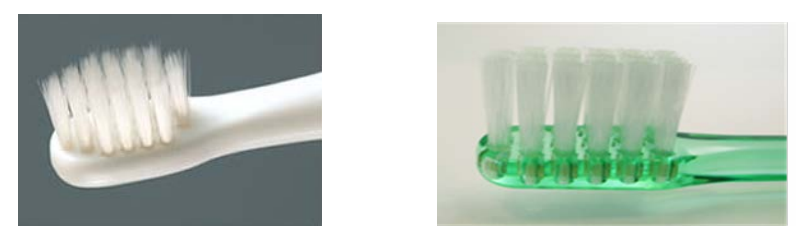

\section{Results}

Values of substance loss $(\mu \mathrm{m}$; means \pm SD) on the treated and control surfaces were $24.6 \pm 3.61$ and $21.5 \pm 3.36$, respectively. There were no significant differences in the average thickness of substance loss between the two areas, indicating that the dentine-abrading action 


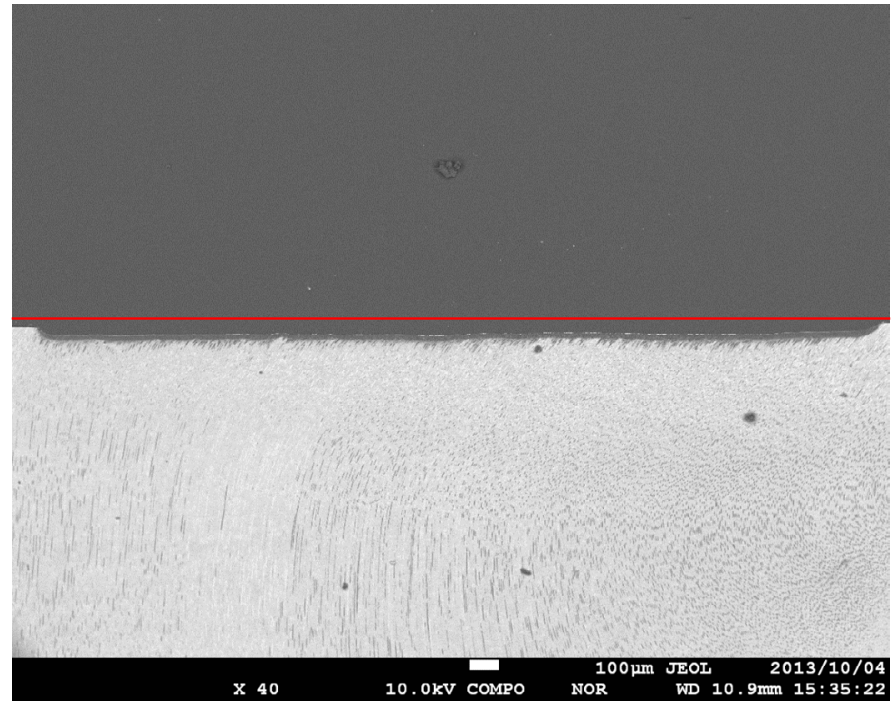

Figure 1. COMPO image $(\times 40)$ of cross-section of whole eroded window. Half of the window (right side) was sonically brushed using bristles with tapered tips and slurry containing $0.5 \% \mathrm{CMC}$, and applying a pressure of $4 \mathrm{~g}$ per $\mathrm{mm}^{2}$. The lower magnification image was used to adjust the tilt of the slab surface to a horizontal plane, indicated as a red line.

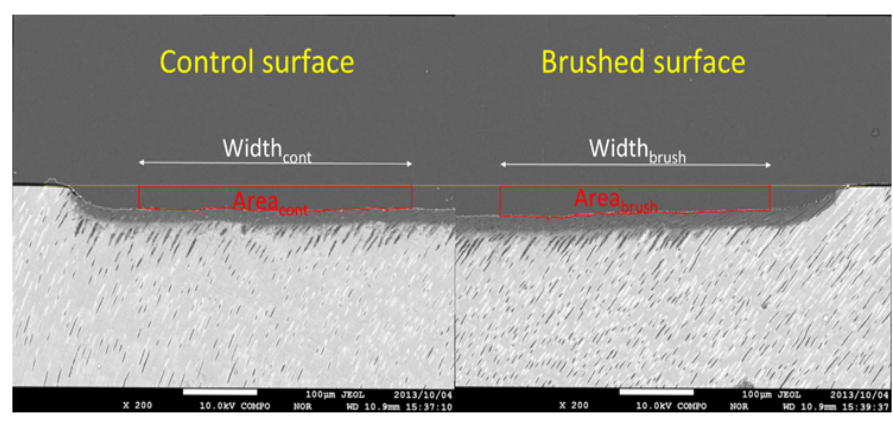

Figure 2. COMPO images $(\times 200)$ of cross-sectioned slabs including the boundary between the eroded and sound dentine. Sample was the same as in Figure 1. Areas of substance loss across some width within the window were measured in COMPO images by image analysis, which calculated abrasion thickness as follows:

$$
\text { abrasion thickness }(\mu \mathrm{m})=\frac{\text { Area }_{\text {rush }}}{\text { Width }_{\text {brush }}}-\frac{\text { Area }_{\text {cont }}}{\text { Width }_{\text {cont }}}
$$

Table 1. Cross tabulation table of three factors and number of samples analyzed. Severa samples that were excluded due to such reasons as breaking slabs or damage of exposed windows, were dealt with as missing values.

\begin{tabular}{|c|c|c|c|c|c|}
\hline \multicolumn{2}{|c|}{ Tip form } & \multicolumn{2}{c|}{ Tapered } & \multicolumn{2}{c|}{ Flat trim } \\
\hline \multicolumn{2}{|c|}{ Brush tension } & $\mathbf{2 g} / \mathbf{m m}^{\mathbf{2}}$ & $\mathbf{4 g} / \mathbf{m m}^{\mathbf{2}}$ & $\mathbf{2 g} / \mathbf{m m}^{\mathbf{2}}$ & $\mathbf{4 g} / \mathbf{m m}^{\mathbf{2}}$ \\
\hline $\begin{array}{c}\text { Slurry } \\
\text { Viscosity }\end{array}$ & CMC $\mathbf{0 . 5} \%$ & 6 & 6 & 8 & 8 \\
\cline { 2 - 7 } & CMC $\mathbf{1 . 0} \%$ & 8 & 5 & 6 & 6 \\
\hline
\end{tabular}

of the sonic toothbrush was smaller than the dentine-eroding action by acid (Figure 3 ).

Analysis by ANOVA indicated that abrasion thicknesses, defined as the difference in loss values between the brushed and control surfaces, were only affected by tip form with no significant interactions among the other factors (Table 2). Brush tension and slurry viscosity was not recognized as significant factors to transmit brushing force onto eroded dentine surface. Eroded dentine wear with a sonic toothbrush was significantly deeper with a tapered tip $(3.82 \pm 2.73)$ than with a flat trim $(2.40 \pm 1.54)$ (Figure 4$)$.

\section{Discussion}

Assessments of dental erosions deal with different methodological approaches to evaluate either surface phenomena such as change of surface hardness or substantial loss of dental hard tissues [15]. However, even though the target of assessing the thickness of eroded dentine loss is the same, a difference in the results by the methods which were used has been pointed out. Passos, et al. [8] reported that no significant correlation was found between surface wear on an eroded dentine through stylus profilometry and focus-variation 3D microscopy. It was also reported that toothbrush abrasion on an eroded dentine measured by surface profilometry was significantly different from that measured by microradiography, showing that profilometry measurements indicated less apparent substance loss than microradiographic results $[6,7]$. However, both methods gave comparable results after the removal of organic material from eroded dentine surface with collagenase, suggesting that the superficial organic matrix deeply influenced the outcome of established methods for quantifying dental hard tissue loss.

On the other hand, significant effects of brushing force were only found on the demineralized organic fraction of eroded dentine [7], so it is important for the evaluation of toothbrush abrasion to identify accurately the outermost surface of the organic layer. Microradiography is a tool for quantification of mineral loss but not of spatial loss of demineralized tissues. In addition, surface profilometry of eroded

Table 2. ANOVA table for three-factor crossed mixed model.

\begin{tabular}{|c|c|c|c|c|c|}
\hline \multicolumn{5}{|c|}{ Dependent Variable: Abrasion thickness } \\
\hline Source & $\begin{array}{c}\text { Type III } \\
\text { Sum of } \\
\text { Squares }\end{array}$ & df & $\begin{array}{c}\text { Mean } \\
\text { Square }\end{array}$ & F & Sig. \\
\hline tip form & 22.778 & 1 & 22.778 & 4.501 & 0.039 \\
\hline brush tension & 3.068 & 1 & 3.068 & 0.606 & 0.440 \\
\hline slurry viscosity & 1.567 & 1 & 1.567 & 0.310 & 0.581 \\
\hline tip form * brush tension & 3.321 & 1 & 3.321 & 0.656 & 0.422 \\
\hline tip form * slurry viscosity & 10.148 & 1 & 10.148 & 2.005 & 0.164 \\
\hline slurry viscosity * brush tension & 0.002 & 1 & 0.002 & 0.000 & 0.986 \\
\hline tip form * brush tension * slurry & 0.780 & 1 & 0.780 & 0.154 & 0.697 \\
\hline viscosity & 227.715 & 45 & 5.060 & & \\
\hline Error & 770.486 & 53 & & & \\
\hline Total & 270.559 & 52 & & & \\
\hline Corrected Total & & & & & \\
\hline
\end{tabular}

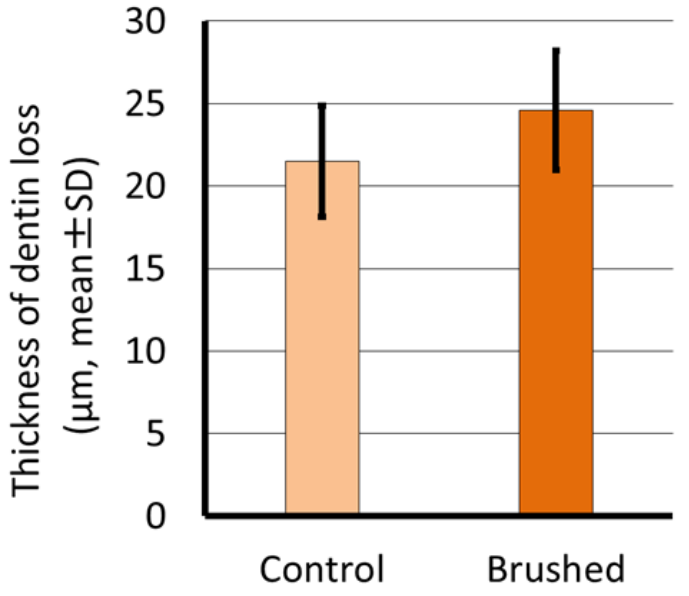

Figure 3. Thickness of dentine loss in brushed and control areas. 


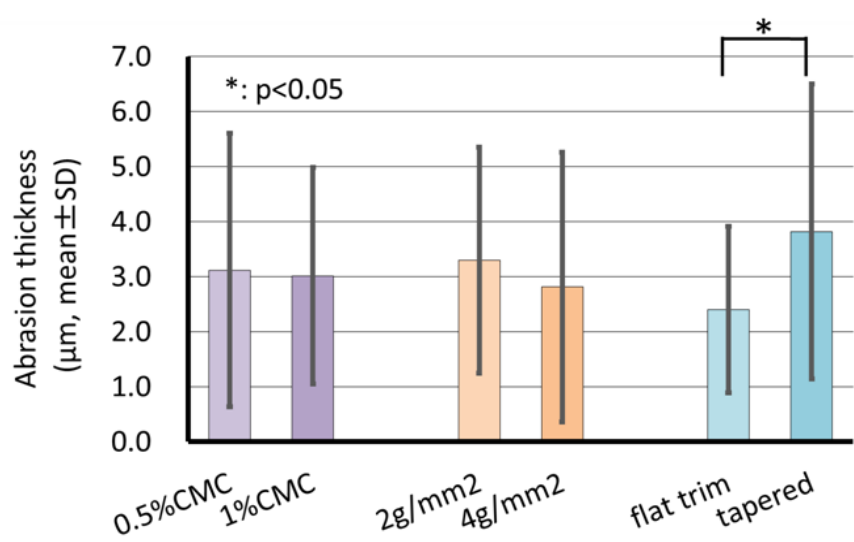

Figure 4. Comparison of abrasion thickness among groups.

dentine might interfere with the exposed collagen matrix. Contact profilometry has a risk of scratching the eroded soft tissue by stylus that may underestimate the results of spatial loss [8]. Therefore, in this study, the erosive dentine ware by a sonic toothbrush was assessed from the spatial loss of demineralized tissue obtained by identifying the outer surface. Although the measured value using this technique could reflect the shrinkage of the organic surface layer.

In vitro study using the same technique as the present study, was carried out to evaluate the influence of acid erosion on dentine and the abrading action of a sonic toothbrush on eroded dentine by measuring the depth of dentinal loss using EPMA [13]. The study design involved a single application of three different erosive liquids (with a $\mathrm{pH}$ range of 2.3 - 3.3) for 60,120 , or 180 minutes, respectively, followed by brushing with either a slurry containing non-fluoridated toothpaste (RDA 108) or water for $1 \mathrm{~min}$ using a force of $0.5 \mathrm{~N}$. Eroded dentine without brushing was served as the control. As a result, the loss of eroded dentin rose with an increasing period of exposure to the acid solutions depending on the $\mathrm{pH}$ of the solutions. Analysis using ANOVA indicated that the thickness of dentinal loss was affected by the kinds of acid solution and erosion time with a significant interaction between these factors, suggesting that this method was useful for the quantitative evaluation of the depth of tissue loss. However, toothbrushing conditions had little influence on the loss of eroded dentine irrespective of toothpaste abrasiveness. It might be due to the relatively greater influence of substance loss by erosion than by toothbrushing wear. Severe erosive conditions were chosen in order to create an amount of tissue loss which might be measurable using the COMPO images, avoiding the fact that the amount of tissue loss might be below the detection limit of the assessment technique.

Milder erosive conditions were applied in this study to quantitatively evaluate the abrading action of a sonic toothbrush than had been done previously. Consequently the eroded dentine wear by sonic toothbrushing was only affected by tip form with no significant interactions among the other factors transmitting brushing force onto eroded dentine surface such as brush tension and slurry viscosity.

Erosion and abrasion of dentine rarely act alone but interact with each other. It has often been stated that eroded dentine is particularly susceptible to abrasive wear. Brushing dentine after an erosive attack by acidic foods and beverages may accelerate abrasive wear of the tissue $[4,5,11]$. In situ study carried out by Attin, et al. [4] to evaluate the effect of intra-oral remineralization on the susceptibility of softened dentine to toothbrushing abrasion demonstrated that for protection of dentine surfaces, at least 30 min should elapse before toothbrushing after an erosive attack.

Toothbrushing wear appears to be influenced by many factors including the frequency, duration, and force of brushing. Ganss, et al. [7] investigated the effects of brushing forces up to $4 \mathrm{~N}$ on mineralized and organic dentine fractions and reported that brushing of the specimens after erosive treatment caused no significant increase in mineral loss regardless of the different brushing forces applied. The COMPO images of this study revealed that demineralized organic layers were clearly present on the experimental surfaces of every specimen. As the demineralized organic dentine matrix was strikingly resistant to mechanical impacts [6,7], the difference in the tissue loss between brushing and not brushing were undetectable under brushing forces applied in our study.

The major factor in dentine wear appears to be the relative dentine abrasivity (RDA) of the toothpaste. The cross over study comparing two toothpastes of differing RDA values (85 and 189) showed significantly increased abrasion of sound dentine by the toothpaste with the higher RDA value indicating that the ratio of abrasion between the two pastes was similar to the ratio of the RDA values [16]. As with sound dentine, abrasion of eroded dentine increases along with the RDA value of the toothpaste slurry and with decreasing filament diameter of the toothbrush [17]. Our results also indicated that a sonic toothbrush with a tapered tip significantly accelerated eroded dentine wear than that with a flat trim. This might be explained by increased retention of slurry using the greater flexion of tapered tips, thus increasing the area of surface contact [18]. The tapered tip form had more filaments contacting the dentine surfaces than the flat end form, possibly transporting toothpaste across the dentine surface more efficiently.

A recent research on dentine abrasion over a simulated long-term period in vitro shows that the power toothbrushes caused significantly higher dentine abrasion compared to the manual toothbrushes using the same brushing force and a highly abrasive toothpaste (RDA 150) [19]. However, the combination of the different slurry viscosities and silica abrasiveness with an RDA value of 125 had also no significant influences on an elevation of eroded dentine wear. The differences in slurry viscosity might be diminished through sonic toothbrush movements of 28,800 strokes/min.

In the present technique, polished surfaces were needed for precise assessment of the erosively induced defects or for creating reference surfaces. Furthermore, the intentionally exaggerated conditions were chosen to measure the depth of substance tissue loss. In the oral cavity, the contact of teeth with an acidic substrate is usually limited to a few seconds before clearance by saliva. For simulating intra-oral erosion as closely as possible, it is desirable to assess the erosive effects on native tooth surfaces. It might be favorable to apply this technique to in situ study using the specimens which were intraorally carried in individual appliances allowing their removal from the oral cavity for further treatment, such as demineralization and brushing. In this aspect, further studies will be needed to clarify which factors are closely related to abrasion of eroded dentine by brushing.

\section{Conclusions}

Abrasion thicknesses, defined as the difference in loss values between the brushed and control surfaces, were only affected by tip form while brush tension and slurry viscosity were not recognized as significant factors in transmiting brushing force onto eroded dentine surface. Eroded dentine wear with a sonic toothbrush was significantly 
deeper with a tapered tip than with a flat trim. Quantitative evaluation of eroded dentine-abrading action by a sonic toothbrush suggested that the influence of factors transmitting brushing force on eroded dentine wear is limited.

\section{Acknowledgments}

This study was supported by Grant-in-Aid for Scientific Research (C) No. 24593178, from the Japan Society for the Promotion of Science.

\section{References}

1. Ganss C (2006) Definition of erosion and links to tooth wear. In: Lussi A (ed): Dental erosion. Monographs in oral science, Karger, Basel.

2. Vanuspong W, Eisenburger M, Addy M (2002) Cervical tooth wear and sensitivity: erosion, softening and rehardening of dentine; effects of $\mathrm{pH}$, time and ultrasonication. J Clin Periodontol 29: 351-357. [Crossref]

3. Zero D, Lussi A (2006) Behavioral factors. In: In: Lussi A (ed): Dental erosion. Monographs in oral science, Karger, Basel.

4. Attin T, Siegel S, Buchalla W, Lennon AM, Hannig C, Becker K (2004) Brushing abrasion of softened and remineralised dentin: An in situ study. Caries Res 38: 62-66. [Crossref]

5. Wiegand A, Lemmrich F, Attin T (2006) Influence of rotating-oscillating, sonic and ultrasonic action of power toothbrushes on abrasion of sound and eroded dentine. $J$ Periodont Res 41: 221-227. [Crossref]

6. Ganss C, Schlueter N, Hardt M, von Hinckeldey J, Klimek J (2007) Effects of toothbrushing on eroded dentine. Eur J Oral Sci 115: 390-396. [Crossref]

7. Ganss C, Hardt M, Blazek D, Klimek J, Schlueter N (2009) Effects of toothbrushing force on the mineral content and demineralized organic matrix of eroded dentine. Eur $J$ Oral Sci 117: 255-260. [Crossref]

8. Passos VF, Melo MA, Vasconcellos AA, Rodrigues LK, Santiago SL (2013) Comparison of methods for quantifying dental wear caused by erosion and abrasion. Microsc Res Tech 76: 178-183. [Crossref]
9. West NX, Hooper SM, O’Sullivan D, Hughes N, North M, Macdonald EL, et al. (2012) In situ randomised trial investigating abrasive effects of two desensitising toothpastes on dentine with acidic challenge prior to brushing. J Dent 40: 77-85. [Crossref]

10. Huysmans MC, Chew HP, Ellwood RP (2011) Clinical studies of dental erosion and erosive wear. Caries Res 45: 60-68. [Crossref]

11. Magalhaes AC, Rios D, Moino AL, Wiegand A, Attin T, Buzalaf MA (2008) Effect of different concentrations of fluoride in dentifrices on dentin erosion subjected or not to abrasion in situ/ex vivo. Caries Res 42: 112-116. [Crossref]

12. Kato K, Tamura K, Nakagaki H (2012) Quantitative evaluation of the oral biofilmremoving capacity of a dental water jet using an electron-probe microanalyzer. Arch oral biol 57: 30-35. [Crossref]

13. Tamura K, Kato K, Soga Y, Shimazaki Y (2014) Quantitative evaluation of loss of eroded dentin using an electron probe micro-analyzer (EPMA). J Dent Hlth 64: 270277.

14. Shellis RP, Addy M (2014) The interactions between attrition, abrasion and erosion in tooth wear In: Lussi A, Ganss C (eds): Erosive tooth wear. Monographs in oral science, Karger, Basel.

15. Attin A, Wegehaupt FJ (2014) Methods for assessment of dental erosion. In: Lussi A, Ganss C (eds): Erosive tooth wear. Monographs in oral science, Karger, Basel.

16. Addy M, Hughes J, Pickles MJ, Joiner A, Huntington E (2002) Development of a method in situ to study toothpaste abrasion of dentine. Comparison of 2 products. $J$ Clin Periodontol 29: 896-900. [Crossref]

17. Wiegand A, Kuhn M, Sener B, Roos M, Attin T (2009) Abrasion of eroded dentin caused by toothpaste slurries of different abrasivity and toothbrushes of different filament diameter. J Dent 37: 480-448. [Crossref]

18. Dyer D, Addy M, Newcombe RG (2000) Studies in vitro of abrasion by different manual toothbrush heads and a standard toothpaste. J Clin Periodontol 27: 99-103. [Crossref]

19. Bizhang M, Schmidt I, Chun YP, Arnold WH, Zimmer S (2017) Toothbrush abrasivity in a long-term simulation on human dentin depends on brushing mode and bristle arrangement. PLoS ONE 12: e0172060. [Crossref]

Copyright: (C2017 Kato K. This is an open-access article distributed under the terms of the Creative Commons Attribution License, which permits unrestricted use, distribution, and reproduction in any medium, provided the original author and source are credited. 